ISSN : 2252-3839 (Print)

ISSN : 2549-2403 (On Line)

DOI : 10.28989/compiler.v9i2.817

http://ejournals.stta.ac.id/index.php/compiler/

\title{
ENGINEERING WEB-BASED INFORMATION SYSTEMS FOR MANAGEMENT OF WOMEN AND CHILD PROBLEM HANDLING ACTIVITIES
}

\author{
Zaidir, Indra Listiawan* \\ Prodi D3 Teknologi Informasi, Fakultas Sains dan Teknologi \\ Universitas Respati Yogyakarta \\ Jl. Adisucipto KM 6.3, Depok, Sleman, Yogyakarta \\ Email Korespondensi : *indra.unriyo@yahoo.com
}

Received: November 4, 2020; Accepted : November 16, 2020; Published : November 20, 2020

\begin{abstract}
The problem of violence against women and children, viewed from an individual as well as a social perspective, can have multiple effects. The effects such as psychological and individual health and the quality of public health. Women and children in everyday life often receive unpleasant treatment from close people and strangers. The many problems of women and children have triggered the formation of a Task Force for Handling Women and Children problems, both at the central and regional levels. PPA Task Force activities include: outreach, identification of conditions and services needed, protection of women and children at the scene, placement and displacement of women and children who experience problems and referrals and / or recommendations. This study aims to produce a system for managing the activities of the task force handling women and children in the village of Katekan Ggantiwarno Klaten. The system development method used is the Waterfall method and is built using PHP programming and MySQL database. The result of this research is a system capable of managing the activities of the task force handling women and children which can provide information with all variations to the task force, village administrators and social services.
\end{abstract}

Keywords: Engineering, Information Systems, PPA Task Force, Women and Children

\section{Latar Belakang Masalah}

Topik masalah perempuan dan anak sering diperbincangkan terutama terkait dengan masalah pelecehan, kekerasan, maupun eksploitasi. Kekerasan terhadap perempuan dan anak dapat mengakibatkan efek ganda, bukan hanya psikologis dan kesehatan individu saja, tetapi juga berdampak pada kualitas kesehatan masyarakat pada umumnya. Perempuan dan anak dalam kehidupan sering mendapat perlakuan yang tidak menyenangkan baik dari orang-orang terdekat maupun orang yang tidak dikenal.

Banyaknya permasalahan perempuan dan anak menyebabkan Kementerian PP dan PA merasa penting membentuk Satuan Tugas Penanganan masalah Perempuan dan Anak (Satgas PPA), baik di tingkat pusat maupun daerah. Keberadaan Satgas PPA untuk melakukan upaya preventif dan kuratif, fungsi penjangkauan terhadap perempuan dan anak yang mengalami permasalahan, identifikasi kondisi dan layanan yang dibutuhkan, melindungi perempuan dan anak dari lokasi kejadian dan hal yang dapat membahayakan dirinya, menempatkan dan mengungsikan perempuan dan anak yang mengalami permasalahan ke Pusat Pelayanan Terpadu Perlindungan Perempuan dan Anak (P2TP2A) atau lembaga lainnya. 
Satgas PPA juga berperan serta mendorong aparat penegak hukum agar dapat menegakkan hukum bagi pelaku kekerasan terhadap perempuan dan anak agar menimbulkan efek jera. Satgas PPA merupakan perpanjangan tangan dari Dinas Sosial (Dinsos) melalui P2TP2A di tingkat desa/kelurahan untuk melakukan pencatatan dan pelaporan kejadian terkait masalah perempuan dan anak. Dinas Sosial akan melakukan komunikasi rutin dengan satgas PPA agar kejadian-kejadian di masyarakat dapat terpantau dengan cepat. Dokumen laporan dari satgas PPA akan dijadikan acuan untuk tindak lanjut penanganan masalah dan digunakan untuk membantu dalam pengambilan keputusan.

Kompleksnya permasalahan yang ada seperti penanganan yang rutin dan terstruktur, petugas yang terbatas, banyak warga yang tidak mau mengungkap masalahnya secara langsung pada yang berwenang, perlu disiati agar pengelolaan data kegiatan satgas PPA bisa praktis dan efisien. Solusi yang diperlukan adalah membangun aplikasi untuk pengelolaan penanganan masalah perempuan dan anak. Jika masalah ini tidak diteliti guna pengembangan sistem, dampaknya yaitu: 1) Pelaporan kejadian masalah perempuan dan anak membutuhkan waktu yang lama, 2) Ketersediaan informasi untuk keputusan untuk tindak lanjut penanganan masalah sangat terbatas, 3) Pekerjaan satgas PPA tidak efisien karena harus mengisi form secara berulang dan tidak terdokumentasi dengan baik.

Penelitian tentang penanganan masalah perempuan dan anak sudah banyak dilakukan, diantaranya: Penelitian tentang Perlindungan Hukum Terhadap Anak Perempuan Korban Kekerasan Seksual di PPA Polresta Banjarmasin [1]. Penelitian ini mengungkap kendala yang dihadapi Unit Pelayanan Perempuan dan Anak memberikan perlindungan hukum yaitu: korban sungkan melapor, pihak keluarga dan masyarakat belum paham dan cenderung menyalahkan korban, adanya pencabutan laporan dari pihak korban, tersangka melarikan diri, kekerasan seksual biasanya dilakukan malam hari, dan kurangnya sarana dan prasarana. Penelitian tentang Pelaksanaan Pendampingan Pusat Pelayanan Terpadu Perlindungan Perempuan Dan Anak (P2TP2A) Wijaya Kusuma Terhadap Anak Korban Kekerasan Seksual Di Kabupaten Gunungkidul [2]. Penelitian ini menyatakan prosedur pendampingan dalam menangani anak korban kekerasan seksual dilakukan dengan tahap pelaporan tindak kekerasan, assessment, pelaksanaan pendampinngan, reintegrasi sosial dan terminasi. Monitoring dilakukan dengan home visit dan evaluasi dilakukan dengan rapat koordinasi penanganan kasus bersama jejaring, rapat internal tim, laporan perkembangan korban yang telah selesai didampingi. Penelitian tentang Efektivitas Komunikasi Antarpribadi Dalam Mencegah Tindak Kekerasan Terhadap Anak [3]. Penelitian ini menyatakan bahwa orangtua di kota Bandung sebagian besar melakukan keterbukaan dalam berkomunikasi dengan anak, khususnya berkaitan dengan kekerasan yang mungkin ada di lingkungan anak. Mereka memiliki sikap positif dan empati terhadap pergaulan anak, yang ditunjukkan dengan upaya mencegah tindak kekerasan pada anak. Kesetaraan dalam keluarga dilakukan untuk membuka partisipasi anak, sehingga anak akan terbuka. Penelitian tentang Rancang Bangun Aplikasi Pelaporan Kekerasan Terhadap Perempuan dan Anak pada DPPPA Provinsi Kalimantan Barat [4]. Hasil pengujian aplikasi menunjukkan bahwa aplikasi pelaporan tindakan kekerasan pada perempuan dan anak dapat digunakan untuk melaporkan dan menampilkan tindakan serta titik lokasi kekerasan. Penelitian tentang Penanganan Kekerasan Terhadap Perempuan Dan Anak Di Provinsi Kalimantan Timur [5]. Penelitian ini menayatakan penanganan korban kekerasan dilakukan sesuai dengan Standar Pelayanan Minimum yang ditetapkan oleh pemerintah dari mulai pelayanan pengaduan hingga pemulangan dan pemberdayaan sesuai hasil assessment, selajutnya dilakukan rujukan/koordinasi dengan pihak terkait sesuai kondisi korban. Penelitian tentang Perencanaan dan Implementasi Perlindungan Perempuan dan Anak Korban Kekerasan di DIY (Studi pada P2TPA "RDU" DIY) [6] . Penelitian ini mengungkap bahwa faktor-faktor yang mempengaruhi implementasi perlindungan perempuan dan anak korban kekerasan yaitu komunikasi, sumber daya, 
disposisi, dan struktur birokrasi sudah berjalan dengan baik walaupun belum optimal. Penelitian tentang Peran Keluarga dan Masyarakat dalam Perlindungan Anak Mengurangi Tindak Kekerasan [7]. Penelitian ini menyatakan bahwa kluster pertama yang berperan dalam perlindungan anak adalah keluarga terdekat, kemudian masyarakat sekitar dan penggerak PKK. Kasus kekerasan yang terjadi sebagian besar pelakunya keluarga dekat. Penelitian tentang Analisis Kebijakan Perlindungan Kekerasan Terhadap Anak Di Kota Makassar [8]. Penelitian ini mengungkap bahwa faktor penyumbang angka kekerasan terhadap anak yang dilupakan yaitu anak itu sendiri yang melakukan tindak kekerasan terhadap anak yang lain. Tindak kekerasan ini lahir dari adanya agresivitas dalam diri anak yang muncul, salah satunya pengaruh keseharian. Penelitian tentang Perlindungan Hukum Preventif Terhadap Kekerasan Perempuan Dan Anak Dalam Perspektif Hukum Hak Asasi Manusia [9]. Penelitian ini menyatakan bahwa perlindungan hukum preventif diharapkan dapat menanggulangi bahkan mencegah kekerasan terhadap perempuan dan anak. Penelitian tentang Sistem Informasi Pengaduan Kekerasan Anak Dan Perempuan Berbasis Web [10]. Penelitian ini menghasilkan program yang dapat membantu para pegawai dan pengguna mendapatkan informasi kekerasan yang terjadi pada masyarakat Kabupaten Inhil dan dapat membantu masyarakat lebih mudah mengakses pengaduan dengan baik, pengguna sistem telah di beri kebebasan untuk mengadukan kekerasan yang terjadi melalui sistem. Penelitian tentang Efek Kesehatan Mental dan Fisik dari Kekerasan Pasangan pada Wanita dan Anakanak [11]. Penelitian ini telah menunjukkan bahwa pelatihan dapat efektif untuk meningkatkan deteksi wanita yang mengalami kekerasan secara signifikan. Depresi seorang wanita tidak akan pernah hilang dan masalah fisiknya kemungkinan besar tidak akan berakhir jika dia tidak diamankan dari pasangan atau mantan pasangannya yang melakukan kekerasan. Respons traumatis seorang anak tidak dapat ditangani sepenuhnya dengan adanya trauma yang sedang berlangsung. Dalam sistem perawatan kesehatan perlu memandang diagnosis kesehatan fisik dan mental para korban sebagai respons normal terhadap cedera, trauma, stres, penghinaan fisiologis, dan psikologis akibat kekerasan.

Berdasarkan beberapa referensi di atas terungkap bahwa penyelesaian pemanfaatan teknologi informasi (dalam bentuk aplikasi khusus) berdasarkan penelusuran di internet masih terbatas, sehingga masalah ini masih cukup menarik untuk diteliti. Perbedaan penelitian ini dengan penelitian yang sudah ada yaitu penelitian ini menyediakan fasilitas kegiatan rutin satgas, proses tindak lanjut dari temuan dan dilengkapi juga fasilitas laporan langsung dari korban/masyarakat serta adanya output yang sangat bervariasi untuk membatu pengambilan keputusan.

\section{Metodologi Penelitian}

Metode penelitian merupakan penentu keberhasilan penelitian, karena dapat menyajikan urutan atau tata cara yang digunakan untuk menyelesaikan permasalahan. Penelitian ini merupakan jenis penelitian kualitatif yang berarti menggunakan pendekatan deskriptif. Data yang dikumpulkan bukan berupa angka, misalnya data dari wawancara, catatan lapangan dan dokumen resmi lainnya. Desain penelitian yang dipakai adalah studi kasus, yang bertujuan agar dapat menggali masalah secara spesifik dan mendalam.

\subsection{Jenis Data dan Teknik Pengumpulan Data}

Data yang dibutuhkan adalah data primer, yaitu data yang diperoleh secara langsung melalui pengumpulan data. Proses pengumpulan data yang akan digunakan adalah observasi, wawancara dan analisis dokumen.

a. Observasi: dilakukan di desa Katekan yang menjadi pusat kegiatan kelompok kerja (pokja) penanganan masalah perempuan dan anak. 
b. Wawancara: dilakukan kepada semua kelompok kerja, masyarakat, dan kepala desa Katekan, Gantiwarno, Klaten.

c. Analisis Dokumen: arsip yang dipelajari adalah dokumen yang terkait kegiatan kelompok kerja penanganan masalah perempuan dan anak yang ada. Arsip utama adalah dokumen pencatatan bulanan di setiap area kerja (Rukun Tetangga-RT/Rukun Warga-RW).

\subsection{Pengembangan Sistem}

Metode pengembangan sistem menggunakan metode Waterfall, terdiri atas beberapa tahap seperti terlihat pada Gambar 1 .

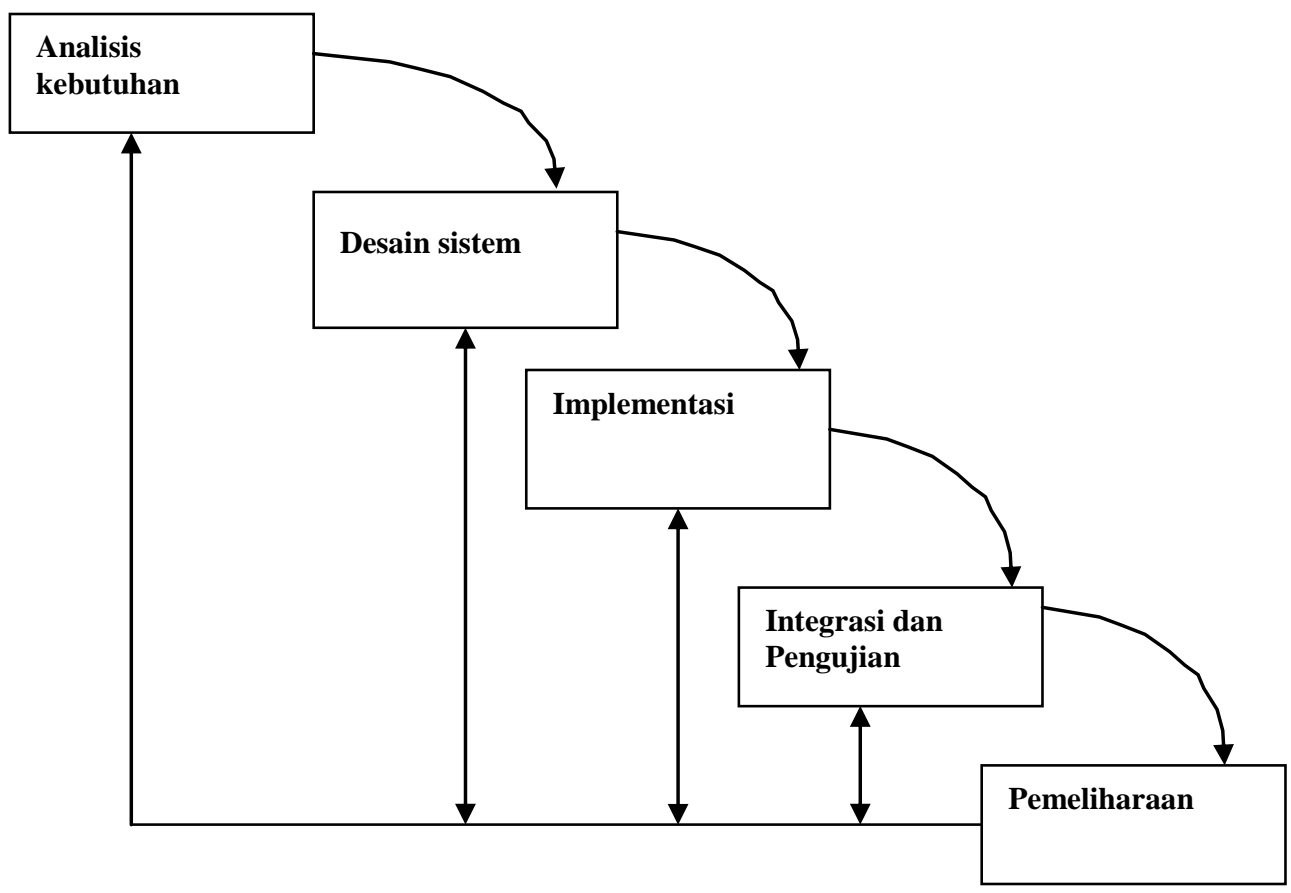

Gambar 1 Metode Waterfall

a. Analisis kebutuhan

Tahap ini menentukan kebutuhan dari penguna terhadap sistem yang dikembangkan dan selanjutnya menentukan spesifikasi sistem yang akan dibangun. Hasil dari proses ini adalah rumusan kelayakan sistem dan rumusan kebutuhan sistem. Pada tahap ini, user dilibatkan secara penuh untuk mendapatkan kondisi existing dan harapan yang diinginkan.

b. Desain sistem

Perancangan sistem didasarkan pada hasil analisis sistem yang telah dilakukan. Perancangan yang dilakukan adalah perancangan model, database, input, dan output.

c. Implementasi

Implementasi merupakan langkah untuk merealisasikan hasil rancangan yang telah dihasilkan dan mendapat persetujuan dari pengguna sistem. Implementasi menggunakan bahasa pemrograman PHP dan basis data MySQL.

d. Integrasi dan pengujian

Pengujian yang dilakukan terhadap sistem adalah pengujian unit, pengujian modul, pengujian sistem dan pengujian integrasi sistem. Metode pengujian yang digunakan adalah black box test, white box test dan alpha test.

e. Pemeliharaan

Pemeliharaan merupakan proses umum pengubahan/pengembangan perangkat lunak setelah diserahkan. 


\section{Hasil dan Pembahasan}

Hasil dari penelitian ini merupakan sebuah sistem berbasis web agar mudah diakses dari mana saja. Rancangan sistem digambar dengan use case untuk fungsionalitas sistem dan relasi antabel untuk menunjukkan kebutuhan basis datanya.

a. Diagram Use Case Sistem

Use Case merupakan sebuah teknik yang digunakan dalam pengembangan sistem informasi untuk menangkap kebutuhan fungsional dari sistem yang bersangkutan. Use case mendeskripsikan sistem, lingkungan sistem, serta hubungan antara sistem dengan lingkungannya. Use case sistem menngambarkan secara umum fungsionalitas sistem yang dikembangkan berdasarkan aturan bisnis yang ada.

Aktor yang terlibat pada sistem ada sebanyak 5 yaitu: Admin. Satgas PPA, Kepala Sekolah, Dinsos, dan Masyarakat. Use case utama ada sebanyak tiga yaitu pendataan, layanan, dan laporan/dashboard. Aktor bisa masuk ke fungsionalitas sistem termasuk/wajib (include) masuk dengan fungsi login. Fungsi login juga termasuk di dalamnya (include) adanya verifikasi login, namun kemungkinan/opsional (extend) error login.

Use case pendataan adalah generalisasi dari use case data Dukuh, data RW, data RT, dan data Pengguna. Use case Layanan adalah generalisasi dari use case data Warga, data Monitoring/Aduan, dan data Tindak Lanjut. Use case Laporan/Dashboard adalah generalisasi dari use case daftar warga, daftar kejadian/aduan, rekap kejadian menurut tahun, rekap kejadian menurut kategori, daftar tindak lanjut dan rekap tindak lanjut.

Aktor masyarakat memiliki akses yang berbeda, agar bisa masuk ke sistem terlebih dahulu harus melakukan register untuk mendapatkan hak akses. Setelah mendapatkan hak akses, boleh melanjutkan/opsional (extend) untuk melakukan login dan melakukan pelaporan kejadian. Bentuk use case sistem dapat dilihat pada Gambar 2.

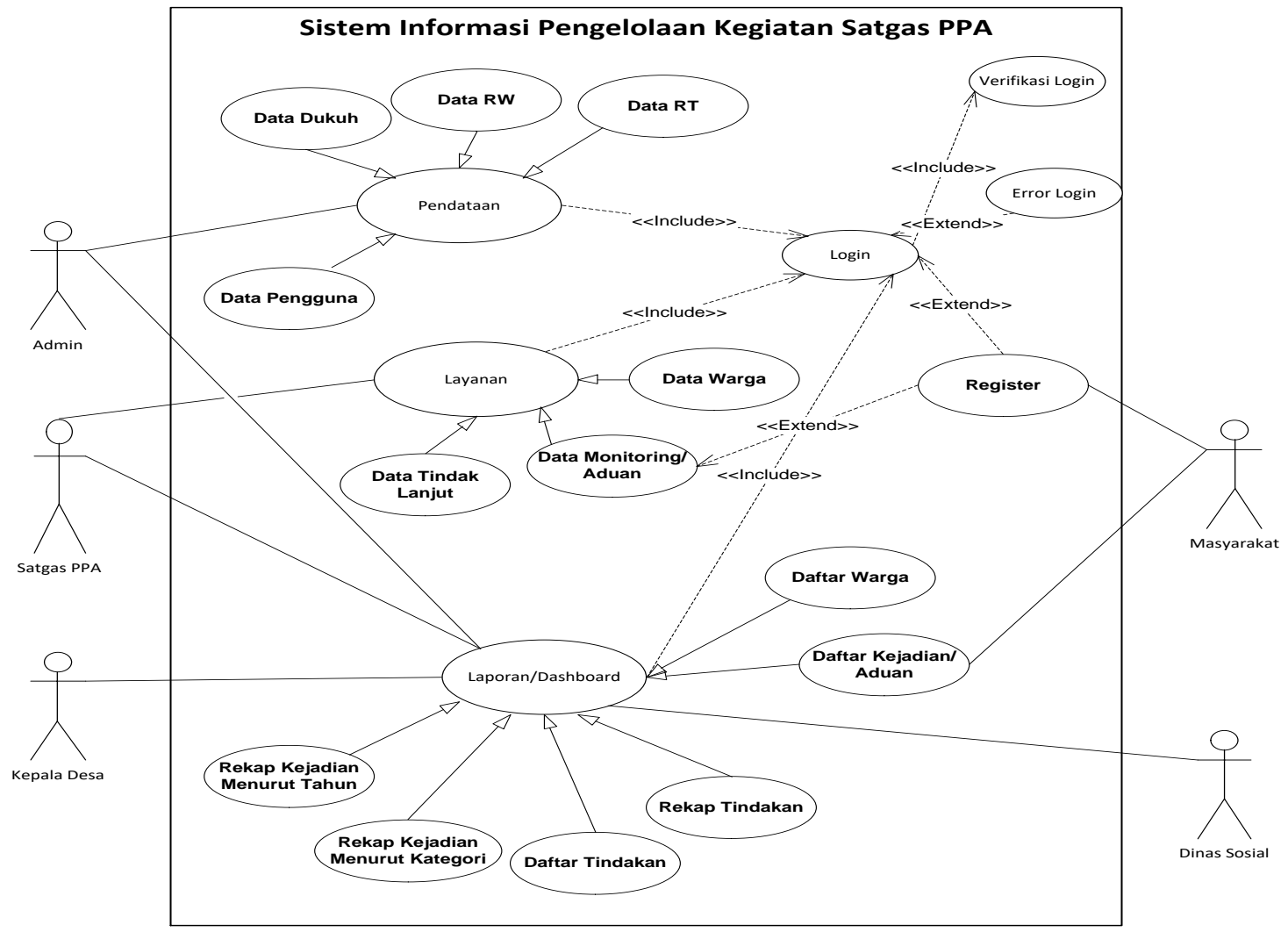

Gambar 2 Use Case Sistem 
b. Relasi Antar Tabel

Database yang dibutuhkan untuk menghasilkan sistem informasi berbasis web untuk pengelolaan kegiatan penanganan masalah perempuan dan anak terdiri atas 7 (tujuh) tabel seperti terlihat pada Gambar 3.

Tabel-tabel yang ada memiliki hubungan satu ke banyak (one to many) kecuali relasi yang terjadi antara tabel kasus (datkas) dengan tabel tindakan kasus (dattin). Pola relasi seperti ini sudah diperhitungkan untuk kemudahan pengolahan dan kemudahan data diambil kembali.

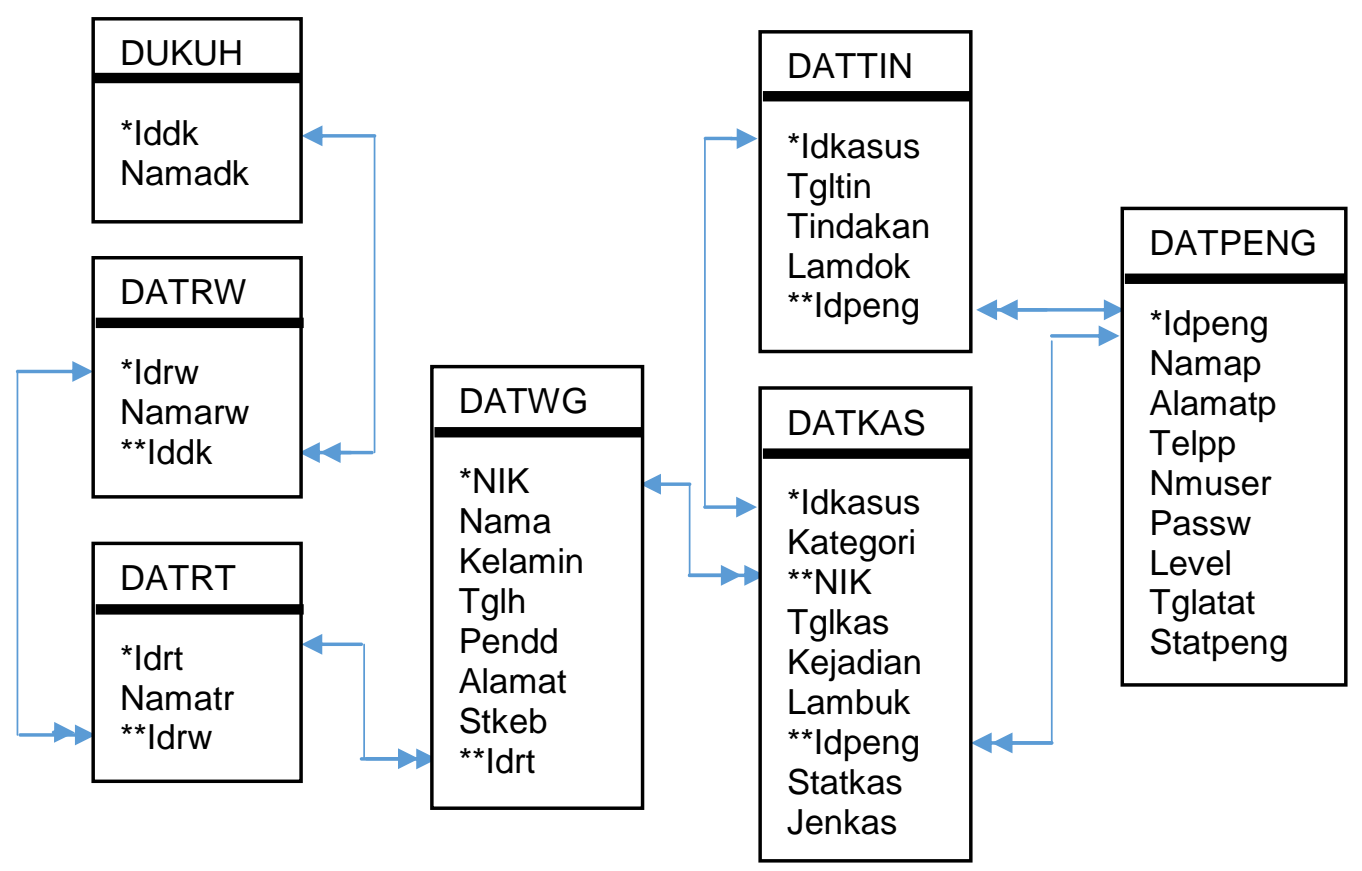

Gambar 3 Relasi Antar Tabel

Rekayasa yang terjadi pada database adalah pada saat pengolahan data kasus/aduan. Satgas PPA bisa mengisi data ke tabel DATKAS tapi jenis kasus (field jenkas) yang terisi adalah "Monitoring". Apabila Masyarakat yang mengisi data kasus/aduan maka jenis kasus yang terisi adalah "Aduan". Status kasus (field statkas) akan terisi secara otomatis "Terlaporkan". Status kasus akan dilakukan perubahan secara otomatis (update) menjadi "Ditindak Lanjuti" pada saat melakukan pengolahan data tindak lanjut. Rekayasa sistem yang terjadi lagi adalah pada saat masyarakat register dan melakukan aduan, proses penyimpanan akan terjadi pada dua tabel sekaligus yaitu tabel pengguna (datpeng) dan tabel kasus (datkas).

c. Tampilan Dashboard

Tampilan ini merupakan tampilan utama atau tampilan yang pertama kali muncul saat aplikasi dipanggil. Saat tampilan ini disediakan beberapa pilihan menu yang bisa diakses. Menu Home merupakan tampilan depan. Menu Data Kasus merupakan informasi mengenai kasus yang pernah ada untuk bisa dilihat oleh semua pihak. Menu Tentang Kami merupakan informasi dasar mengenai aplikasi. Menu Kontak Kami merupakan informsai mengenai pembuat aplikasi. Menu Register adalah fasilitas yang disediakan untuk masyarakat agar bisa mengakses aplikasi dengan melakukan register terlebih dahulu. Menu Login adalah untuk melakukan proses login oleh semua pengguna. Tampilan dashboar secara lengkap dapat dilihat pada Gambar 4. 


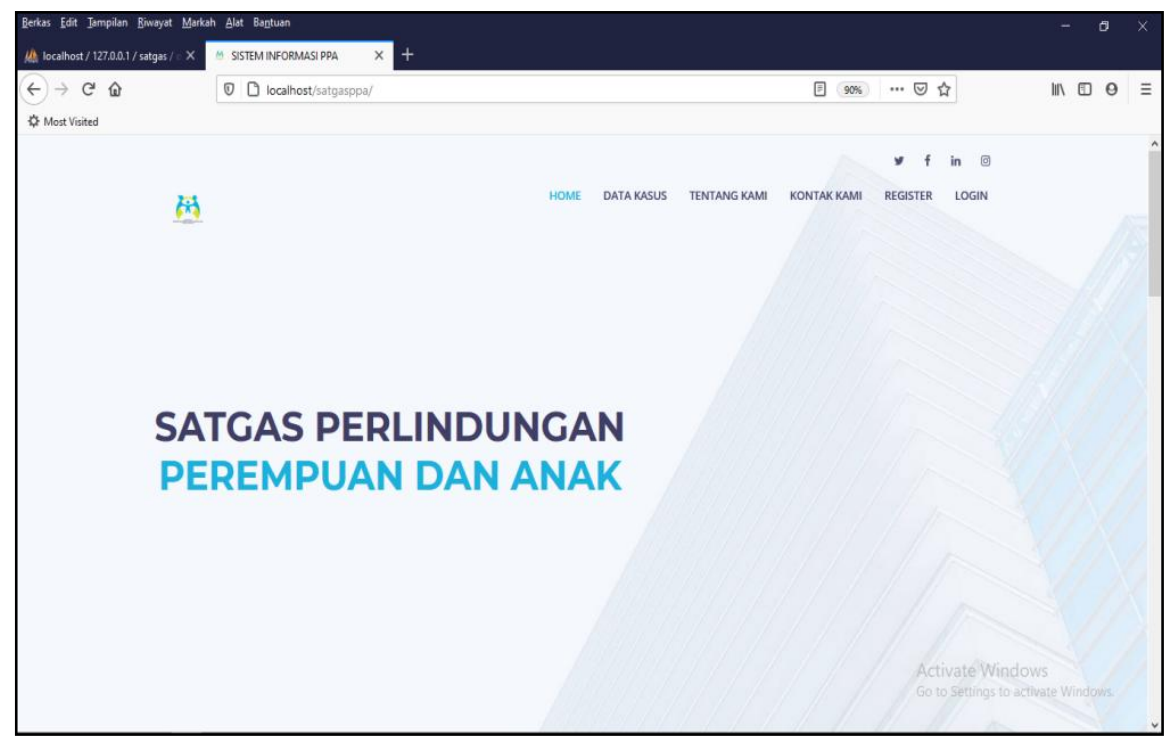

Gambar 4 Tampilan Dashboard

d. Tampilan Login

Para pengguna yang akan masuk ke aplikasi untuk melakukan interaksi lebih lanjut harus melakukan proses Login. Bentuk tampilan proses login dapat dilihat pada Gambar 5.

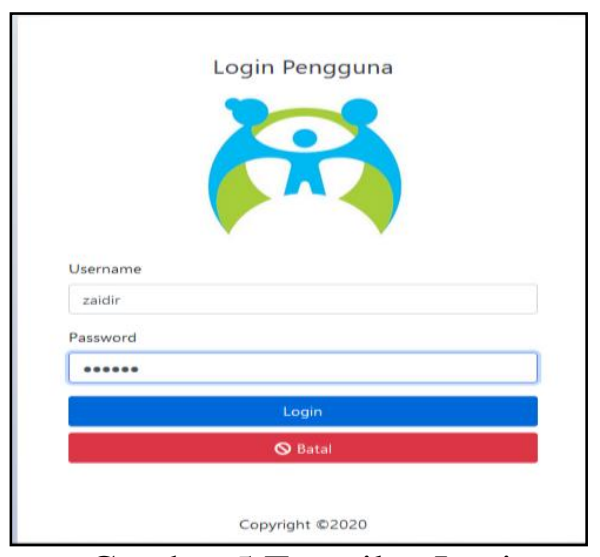

Gambar 5 Tampilan Login

Data yang harus dimasukkan adalah nama pengguna (user name) dan sandi (password). Jika nama user dan sandi tidak cocok akan ditampilkan pesan kesalahan. Jika nama pengguna dan sandi cocok, maka akan diteruskan ke halaman yang sesuai berdasarkan level pengguna.

e. Halaman Kepala Desa/Dinsos

Pengguna yang sudah melakukan proses login, akan disajikan halaman masing-masing sesuai level atau kewenangannya. Pengguna yang memiliki akses sebagai Admin, maka bisa melakukan pengolahan data dasar seperti pengolahan data dukuh, data RW, data RT dan data pengguna. Admin juga bisa melihat informasi yang sifatnya umum. Pengguna yang memiliki akses sebagai Satgas PPA bisa melakukan pengolahan data warga, data kasus/monitoring, dan data tindak lanjut. Satgas PPA juga diberi akases untuk melihat informasi umum. Pengguna yang memiliki akses sebagai masyarakat hanya bisa melakukan pengisian data aduan yang akan diteruskan sebagai 
kejadian/kasus. Pengguna yang memiliki akses sebagai Kepala Desa atau Dinsos, hanya bisa melihat informasi seperti terlihat pada Gambar 6 .

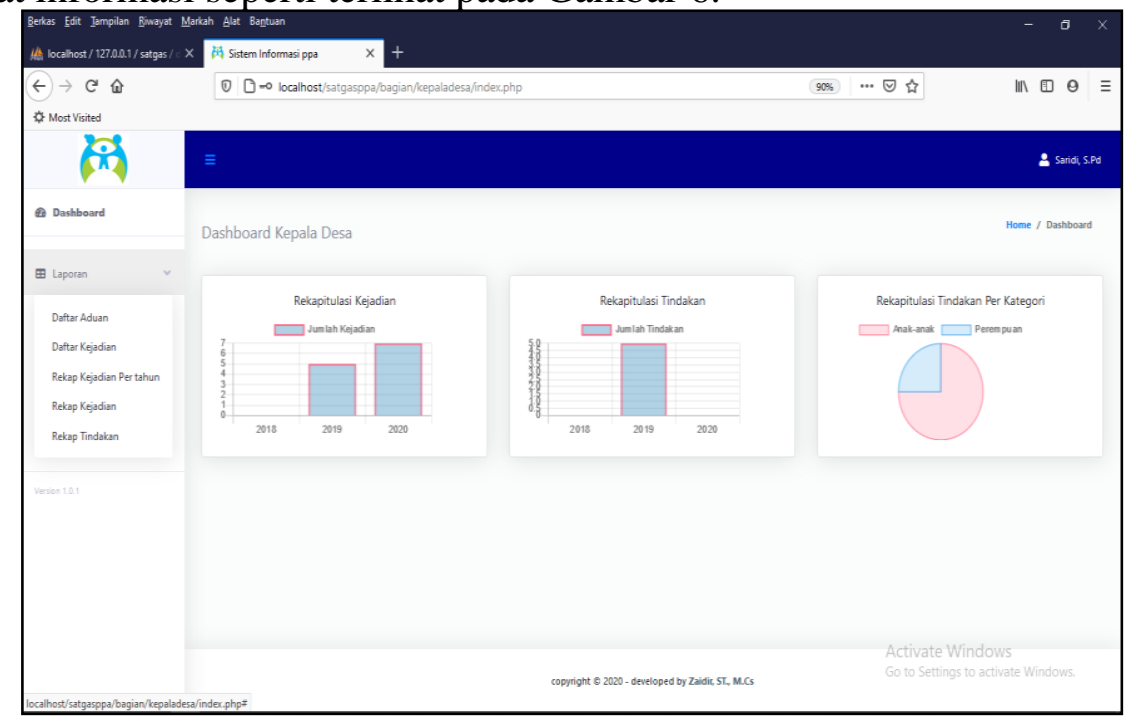

Gambar 6 Tampilan Halaman Kepala Desa

Pada tampilan dashboard disajikan grafik mengenai rekapitulasi kejadian, rekapitulasi tindakan yang dapat membantu dalam pengambilan keputusan. Pada menu laporan disediakan sebanyak lima buah pilihan jenis laporan yang bisa ditampikan dalam bentuk tabel, hal ini tentu akan semakin meningkatkan pengetahuan pihak yang bersangkutan terhadap pengelolaan data penanganan masalah perempuan dan anak.

f. Pengolahan Data Warga

Pengolahan data warga merupakan kewenangan dari Satgas PPA berdasarkan wilayah kerja masing-masing. Data warga ini akan menjadi acuan dalam melakukan catatan kasus yang terjadi tiap wilayah RT. Bentuk tampilan pengolahan data warga dapat dilihat pada Gambar 7.

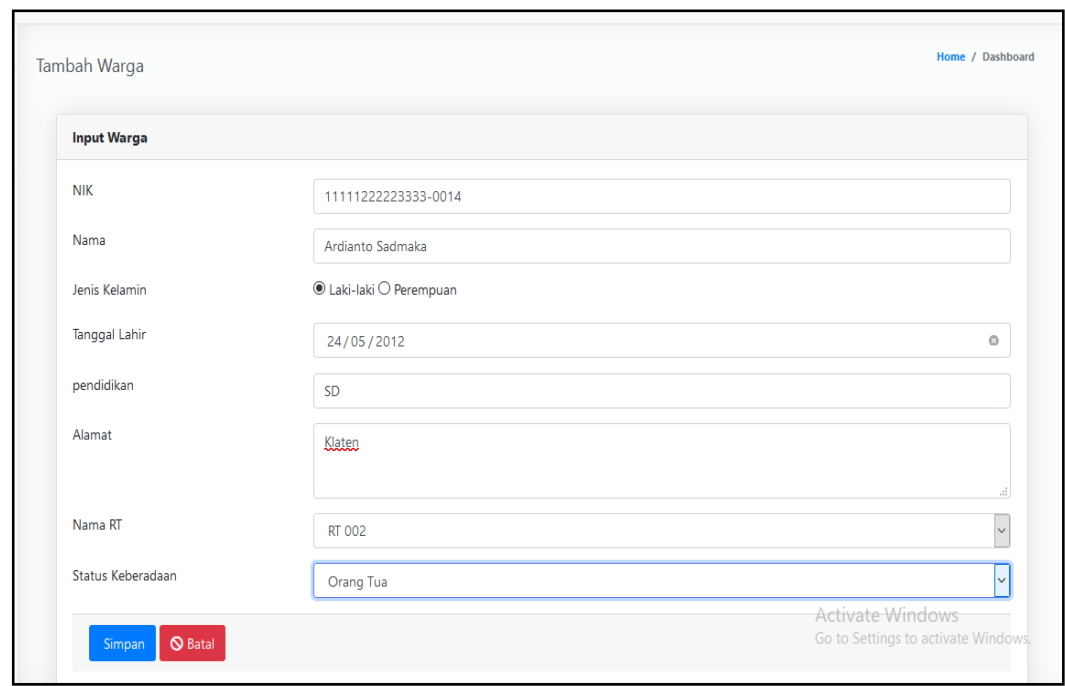

Gambar 7 Tampilan Pengolahan Data Warga

Pada pengolahan data warga, NIK menjadi isian paling penting yang dijadikan sebagai kunci pengenal dari setiap warga. Isian lain adalah informasi pendukung yang dianggap 
Engineering Web-Based Information Systems for Management of Women and Child Problem...

cukup penting, terutama mengenai wilayah RT tempat tinggal warga yang bersangkutan.

g. Pengolahan Data Kasus/Aduan

Pengolahan data kasus ini merupakan pengolahan utama yang dilakukan secara rutin oleh Satgas PPA. Data ini juga mirip dengan data aduan dari masyarakat. Bentuk tampilan pengolahan data kasus/aduan dapat dilihat pada Gambar 8.

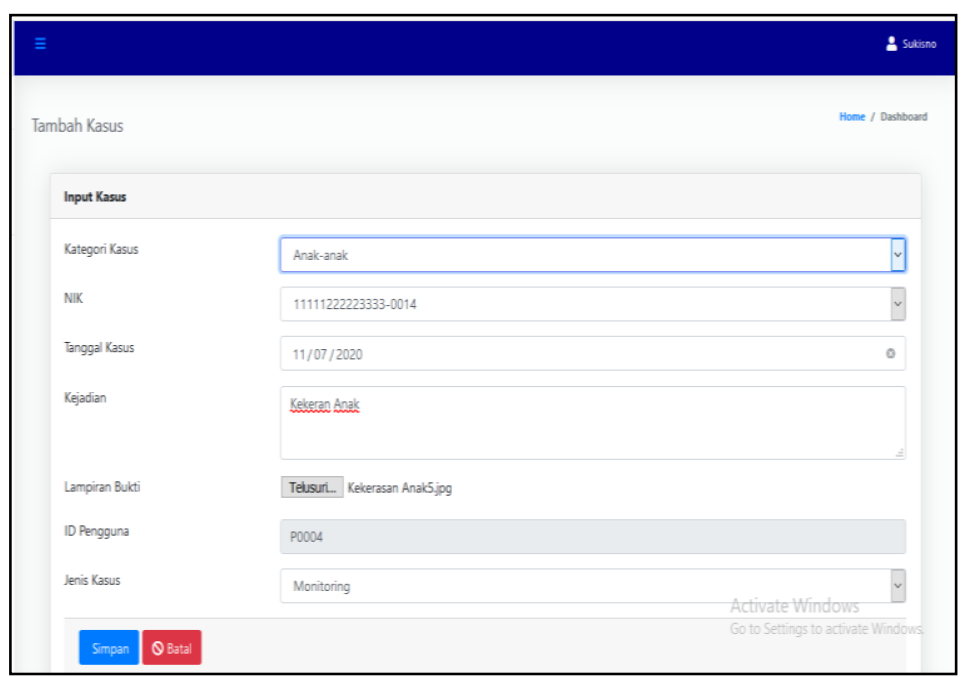

Gambar 8 Tampilan Pengolahan Data Kasus/Aduan

Kategori kasus menjadi hal yang mutlak harus ditentukan, yaitu kasus Perempuan atau Anak. Selanjutnya harus ditentukan identitas warga yang dicatat atau yang mejadi obyek kasus/aduan (bila NIK tidak muncul, maka harus masuk ke pengolahan data warga dulu). Setiap kasus/aduan harus dilengkapi oleh dokumen sebagai lampiran bukti (bisa foto atau dokumen kartu keluarga)

h. Tampilan Laporan Daftar Kasus

Jenis laporan yang tersedia pada aplikasi ini cukup banyak dan cukup bervariasi. Ada laporan yang sifatnya detail dan ada laporan yang sifatnya tersaring. Laporan terinci dicontohkan oleh laporan daftar kasus seperti terlihat pada Gambar 9.

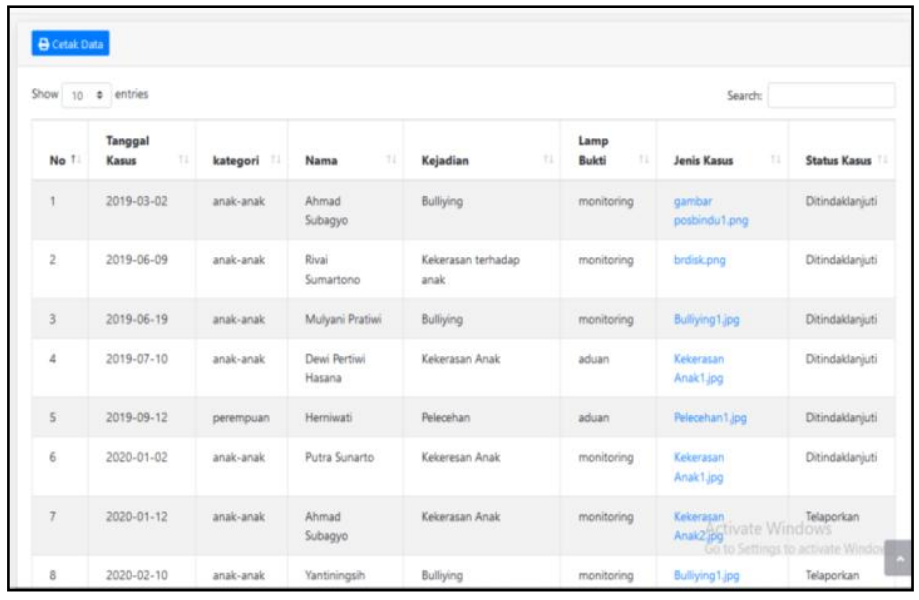

Gambar 9 Tampilan Laporan Daftar Kasus 
Kelemahan dari sistem yang dihasilkan adalah karena masih berbasis web maka belum begitu efektif dan efisien untuk digunakan oleh para pemangku kepentingan terutama satgas PPA dan masyarakat.

\section{Kesimpulan}

Sistem informasi berbasis web untuk pengelolaan kegiatan penanganan masalah perempuan dan anak, mampu mengatasi kesulitan dalam pengelolaan data dan monitoring kegiatan serta otomatisasi berjalan dengan baik. Sistem yang dihasilkan juga dapat menyediakan kebutuhan informasi dengan berbagai variasi bagi satuan tugas, pengurus desa dan dinas sosial untuk membantu pengambilan keputusan. Sistem ini untuk masa yang akan datang bisa dikembangkan dengan berbasis mobile sehingga lebih efisien dan efektif bagi masyarakat dan satgas PPA.

\section{Daftar Pustaka}

[1] A. Syaufi, "Perlindungan Hukum Terhadap Anak Perempuan Korban Kekerasan Seksual di PPA Polresta Banjarmasin," Muwazah, vol. 9, no. 1, pp. 16-28, 2017.

[2] J. R. Derna, "Pelaksanaa Pendampingan Pusat Pelayanan Terpadu Perlindungan Perempuan dan Anak (P2TP2A) Wijaya Kusuma Terhadap Anak Korban Kekerasan Seksual di Kabupaten Gunungkidul," 629-641, vol. 7, no. 6, 2018.

[3] R. Rinawati and D. Fardiah, "Efektivitas Komunikasi Antarpribadi Dalam Mencegah Tindak Kekerasan Terhadap Anak," Jurnal Penelitian Komunikasi, vol. 19, no. 1, pp. 29-40, 2016.

[4] S. P. A. Alkadri and R. W. S. Insani, "Rancang Bangun Aplikasi Pelaporan Kekerasan Terhadap Perempuan dan Anak pada DPPPA Provinsi Kalimantan Barat," Jurnal Edukasi dan Penelitian Informatika, vol. 5, no. 3, pp. 329-337, 2019.

[5] D. Z. Indrawati, O. Kondorura and M. S. AF, "Penanganan Kekerasan Terhadap Perempuan dan Anak di Provinsi Kalimantan Timur," Jurnal Administrative Reform, vol. 6, no. 3, pp. 141-152, 2018.

[6] Y. K. Adiyuwana, "Perencanaan dan implementasi perlindungan perempuan dan anak korban kekerasan di DIY (Studi pada P2TPA "RDU” DIY)," Jurnal Ilmiah Administrasi Publik (JIAP), vol. 2, no. 1, pp. 27-37, 2016.

[7] A. Mardiyati, "Peran Keluarga dan Masyarakat dalam Perlindungan Anak Mengurangi Tindak Kekerasan," Jurnal PKS, vol. 14, no. 4, pp. 453-464, 2015.

[8] Satriawan, Alfiana, H. Fasya, A. F. Amelia and A. A. Yani, "Analisis Kebijakan Perlindungan Kekerasan Terhadap Anak di Kota Makassar," Jurnal Analisis dan Kebijakan Publik, vol. 3, no. 1, pp. 37-48, 2017.

[9] A. L. Suryamizon, "Perlindungan Hukum Preventif Terhadap Kekerasan Perempuan dan Anak Dalam Perspektif Hukum Hak Asasi Manusia," Marwah: Jurnal Perempuan, Agama dan Jender, vol. 16, no. 2, pp. 112-126, 2017.

[10] R. Oktafiani and F. Yunita, "Sistem Informasi Pengaduan Kekerasan Aanak dan Perempuan Berbasis Web," Jurnal SISTEMASI, vol. 7, no. 1, pp. 1-14, 2018.

[11] J. C. Campbell and L. A. Lewandowski, "Mental and physical health effects of intimate partner violence on women and children," ThE Psychiatric Clinics of North America, vol. 20, no. 2, pp. 353-374, 1997. 